\title{
Dependence on the use of fire by rural actors to the land management in the Amazon
}

\author{
Nathália Silva de Carvalho ${ }^{*^{*}}$, Ana Carolina Moreira Pessôa ${ }^{l}$, Liana Oighenstein Anderson ${ }^{2}$
}

\author{
${ }^{1}$ Instituto Nacional de Pesquisas Espaciais (INPE), São José dos Campos, Brasil; ${ }^{2}$ Centro Nacional de \\ Monitoramento e Alertas de Desastres Naturais (CEMADEN), São José dos Campos, Brasil \\ *E-mail: nathalia.carvalho@inpe.br
}

\begin{abstract}
Although most forest fire occurrences in the Amazon is associated to human activities, the understanding of the influence of rural actors (small, medium and large landholders) is still poorly explored in the literature. This research objective was to investigate the dependence on the use of fire by rural actors and which are the implications of this practice on forest areas and carbon emissions. The study area includes $89 \%$ of Amazon biome, in the Brazilian territory. The product of burned area was derived from the mapping of the product MODIS/MOD09, for the period between June and November 2015. We analysed 384,456 rural private properties that were declared in the Rural Environmental Registry (CAR). According to the number of fiscal modules (FM), each rural property (RP) was classified as small $(\mathrm{RP} \leq 4 \mathrm{FM})$, medium $(4 \mathrm{FM}>\mathrm{RP} \leq 15)$ or large (RP > 15FM). Burning scars were registered in $10 \%$ of analysed properties, considering all types of land use/cover, except forest areas. Small and large properties represented $80 \%(n=32,453)$ and $7 \%(n=13,787)$ of the total, respectively. In respect to burning scars in forest areas, 342,635 ha were affected by fire resulting in the emission of $0.0107 \mathrm{Pg} \mathrm{C}$. Small properties contributed with $\sim 30 \%$ of the total of this burned area and carbon loss, being equivalent to $18 \%$ of area of forests $(618,495 \mathrm{ha})$ situated in these properties. On the other hand, large properties contributed with $\sim 50 \%$ of the total of burned areas in forests and carbon emissions, corresponding to only $2 \%$ of the forest area inside these properties (7,947,336 ha). The inverse relationship between the use of fire and the size of the property can be determined by the availability of financial resources to land management. Hence, it is possible to infer a higher dependence on this practice by small landholders. However, this condition does not imply necessarily in a higher impact on forest areas and carbon emissions. Our estimates showed that large landholders have an expressive contribution to forest degradation. This stratification by rural actors is important to improve the definition and implementation of forest management and fire control measures.
\end{abstract}

Keywords: Forest Code, SICAR, family farming, environmental legislation. 